\title{
Dendritic cell vaccination and other strategies to tip the balance of the immune system
}

\author{
DC2007 5th international meeting, July 16-18, Bamberg, Germany
}

\author{
Niels Schaft • Katrin Birkholz • Christian Hofmann • \\ Martina Schmid · Gabi Theiner · Jan Dörrie
}

Published online: 27 February 2008

(C) Springer-Verlag 2008

\section{Erratum to: Cancer Immunol Immunother DOI 10.1007/s00262-007-0443-8}

Due to an oversight, two summaries of presentations held at this meeting were not integrated into the text. We apologize to the speakers for this mistake. The summary of the presentation of Pierre Coulie should have been in the section "Cancer vaccination in general", and the summary of the presentation of Ugur Sahin should have been in "RNA electroporation". These are presented here:

(addition to "Cancer vaccination in general")

Pierre Coulie (Université catholique de Louvain, Belgium) introduced data from vaccination trials with a MAGE-A3 peptide or with ALVAC-MAGE (a canarypox virus containing MAGE-A3 and -A1 minigenes) about the numbers of anti-vaccine $\mathrm{T}$ cells. Frequencies of antiMAGE-A3 $\mathrm{CD}^{+} \mathrm{T}$ cells in blood were low (around $10^{-5}$ ), but higher in regressors than in progressors, indicating a correlation between clinical outcome and anti-vaccine T-cell responses [1]. Vaccination with eight peptides plus CpG did not lead to better responses in most patients. Two peptides (derived from NY-ESO-1 and NA-17) seemed more immunogenic or boosted pre-existing responses. The immunogenicity of DC-presented peptides was clearly better, shown by a comparison with data from a trial with NY-ESO-1 and MAGE-A10 peptide-loaded DC. To analyze

The online version of the original article can be found under doi:10.1007/s00262-007-0443-8.

N. Schaft $(\triangle) \cdot$ K. Birkholz $\cdot$ C. Hofmann $\cdot$ M. Schmid .

G. Theiner · J. Dörrie

Department of Dermatology, University Hospital Erlangen,

Hartmannstraße 14, 91052 Erlangen, Germany

e-mail: niels.schaft@uk-erlangen.de the anti-vaccine T cells, CTL clones from patients vaccinated with peptide (or ALVAC) or with peptide-pulsed DC were compared. The affinity and lytic capacity of the clones were similar, but clones from DC-vaccinated patients produced more IL-10 and less granzyme $\mathrm{K}$ and $\mathrm{H}$. Notably, all patients had a pre-existing, tumor-specific T-cell response with frequencies up to $10^{-3}$ [2]. Coulie introduced a model explaining the observations made in tumor vaccination. Some tumor-specific $\mathrm{T}$ cells can be present in the tumor before vaccination, but are either anergic and suppressed, or recognize antigens that are lost or down-regulated. When new, vaccine-specific clones are induced by the therapy, they "spark" an immune reaction in the tumor. This happens either by breaking a local suppressive environment, or by increasing antigen presentation through IFN $\gamma$, or by inducing the priming of new CTL clones, specific for previously untouched tumor antigens. Clinical trials combining vaccines and local immunomodulation may promote these mechanisms, leading to increased clinical efficacy.

(addition to "RNA electroporation")

Ugur Sahin (Johannes Gutenberg University Mainz, Germany) investigated decay kinetics of protein and epitopes after RNA transfection in immature and mature DC using two model RNAs (i.e., EGFP- or $\mathrm{OVA}_{\text {aa256-267 }}$ encoding RNA). By genetically modifying the RNA-production vector, they found that the best RNA, considering stability, translation and processing efficiency, is produced with a vector that has a long (120 bases) polyA tail, which was digested by an enzyme creating a clean A-nucleotide overhang, and has two $3^{\prime} \beta$-globin UTRs [3]. Stimulation with DC electroporated with $\mathrm{OVA}_{\mathrm{aa} 256-267}$-encoding RNA generated with this vector led to higher antigen-specific $\mathrm{CD}^{+}$T-cell numbers with improved effector functions, compared to wild-type RNA. 
To increase the $\mathrm{CD}^{+} \mathrm{T}$-cell response (i.e., to retarget the antigen into the $\mathrm{MHC}-\mathrm{cl}$. II pathway), an $\mathrm{MHC}-\mathrm{cl}$. I trafficking domain (MITD) [4-6], was introduced into the RNA production vector. CMVpp65 and NY-ESO-1 RNA with MITD electroporated into $\mathrm{DC}$ to stimulate $\mathrm{CD}^{+} \mathrm{T}$ cells resulted in a better proliferation and an increased cytokine production of these cells. These $\mathrm{T}$ cells were further characterized by selecting single tetramer-positive and cytokine-producing cells. Via a single cell PCR, the TCR $\alpha$ / $\beta$ variable regions were cloned and transferred by RNA electroporation into T cells. By using K562 cells, transfected with each HLA-subtype, and pp65 peptide pools, the HLA-restriction and epitope specificity of these TCR were determined. Furthermore, the mode of RNA transfection into DC was investigated. Adoptive transfer of RNA-electroporated DC may be bypassed if the pharmacologically improved RNA could be used for in vivo passive pulsing. Intranodal (i.n.) immunization with naked RNA in mice was tried, resulting in an efficient uptake of RNA by $\mathrm{CD} 11^{+} \mathrm{DC}$ in the LN. Immunization of naïve mice with OVA ${ }_{\mathrm{aa} 256-267^{-}}$ encoding RNA resulted in strong expansion of $\mathrm{CD}^{+} \mathrm{T}$ effectors, and adoptive transfer of OT-I SIINFEKL-specific memory cells followed by RNA immunization resulted in expansion of memory $\mathrm{CD}^{+} \mathrm{T}$ cells. This suggests that in vivo passive pulsing is possible with the optimized RNA.

\section{References}

1. Lonchay C, Van Der Bruggen P, Connerotte T, Hanagiri T, Coulie P, Colau D, Lucas S, Van Pel A, Thielemans K, van Baren N, Boon $\mathrm{T}$ (2004) Correlation between tumor regression and $\mathrm{T}$ cell responses in melanoma patients vaccinated with a MAGE antigen. Proc Natl Acad Sci USA 101(Suppl 2):14631-14638

2. Germeau C, Ma W, Schiavetti F, Lurquin C, Henry E, Vigneron N, Brasseur F, Lethe B, De Plaen E, Velu T, Boon T, Coulie PG (2005) High frequency of antitumor T cells in the blood of melanoma patients before and after vaccination with tumor antigens. J Exp Med 201:241-248

3. Holtkamp S, Kreiter S, Selmi A, Simon P, Koslowski M, Huber C, Tureci O, Sahin U (2006) Modification of antigen-encoding RNA increases stability, translational efficacy, and T-cell stimulatory capacity of dendritic cells. Blood 108:4009-4017

4. Lizee G, Basha G, Tiong J, Julien JP, Tian M, Biron KE, Jefferies WA (2003) Control of dendritic cell cross-presentation by the major histocompatibility complex class I cytoplasmic domain. Nat Immunol 4:1065-1073

5. Kreiter S, Konrad T, Sester M, Huber C, Türeci Ö, Sahin U (2007) Simultaneous ex vivo quantification of antigen-specific CD4+ and $\mathrm{CD} 8+\mathrm{T}$ cell responses using in vitro transcribed RNA. Cancer Immunol Immunother 56:1577-87

6. Kreiter S, Selmi A, Diken M, Sebastian M, Osterloh P, Schild H, Huber C, Türeci Ö, Sahin U (2008) Increased antigen presentation efficiency by coupling antigens to MHC class I trafficking signals. J Immunol 180:309-318 